IP $\rightleftharpoons$ B

\title{
A silvicultura do eucalipto no estado de Goiás: um registro histórico via sensoriamento remoto
}

\author{
Escleide Gomes Cabral ${ }^{1}\left(\mathbb{D}\right.$, Sybelle Barreira ${ }^{2 *}$ (D), Manuel Eduardo Ferreira ${ }^{2}$ (D) Lázaro Gabriel de Oliveira Araújo $^{2}$ (i) \\ ${ }^{1}$ Universidade Federal de Goiás, Escola de Agronomia, Avenida Esperança, s/n., Campus Samambaia, CEP 74690-900, Goiânia, GO, Brasil \\ Universidade Federal de Goiás, Instituto de Estudos Socioambientais, Avenida Esperança, s/n., Campus Samambaia, CEP 74690-900, Goiânia, GO, Brasil
}

"Autor correspondente:

sybelle.barreira@gmail.com

Termos para indexação:

Uso do solo

Cobertura florestal

Landsat

Index terms:

Land use

Forest plantations

Landsat

Histórico do artigo:

Recebido em 07/05/2018

Aprovado em 21/05/2019

Publicado em 31/12/2019
Resumo - A demanda global por alimentos e energia vem crescendo nas últimas décadas, frente a uma população mundial estimada em quase 10 bilhões de pessoas em 2050. Junto com este fenômeno, crescem também a pressão para ampliação da fronteira agrícola, para plantio de grãos e de florestas. A presente pesquisa teve como objetivo mapear as áreas de silvicultura no estado de Goiás, por meio de técnicas de sensoriamento remoto, entre os anos de 2002 e 2015. Foram utilizadas imagens do sensor Operational Land Imager (OLI) do satélite Landsat-8, processadas nos softwares Arcgis ${ }^{\circledR}$ e ENVI ${ }^{\circledR}$. Aárea com florestas plantadas foi estimada, ao longo deste período, por meio de classificação digital supervisionada, método de máxima verossimilhança (Maxver). Verificou-se consideráveis avanços em termos de áreas plantadas em Goiás, constatando-se em 2002 aproximadamente 50.425 ha de floresta plantada, atingindo 162.516 ha em 2015 . As mesorregiões goianas com os maiores plantios de florestas foram a Sul, Leste e Norte. A distribuição espacial dos plantios se caracteriza por pequenas áreas e por uma produção não verticalizada dos produtores. Estas informações, de caráter inédito e estratégico, podem orientar a expansão e o aumento de produtividade do setor, conciliando este processo com a conservação ambiental do bioma Cerrado.

\section{Eucalyptus silviculture in the state of Goiás: a historical record through remote sensing}

\begin{abstract}
Global demand for food and energy has grown intensely in recent decades, facing an estimated 10 billion people in the world by 2050. Along with this phenomenon, there are also growing areas for planting grains and commercial forests. In this context, the main objective of this work is to map the areas of forestry in the state of Goiás by remote sensing techniques, between the years of 2002 and 2015, verifying the location and quantification of the main planting areas. Therefore, images from the Operational Land Imager (OLI) of the Landsat-8 satellite were processed in the Arcgis ${ }^{\circledR}$ and ENVI ${ }^{\circledR}$ softwares. Thus through a supervised digital classification by the maximum likelihood method, we estimated the area with planted forests in the state. After the classification, it was verified that there were considerable advances in terms of areas planted in Goiás, noting that in 2002 there were approximately 50,425 ha of planted forest, reaching 162,516 ha in 2015 . The Goiás mesoregions with the largest forest plantations were the South, East and North, while South and East are the largest producers of firewood and timber. The spatial distribution of the plantations is characterized by small areas and non-vertical production of the producers. This unprecedented and strategic information can better guide the expansion and increase the productivity of the sector, reconciling this process with the environmental conservation of the Cerrado biome.
\end{abstract}




\section{Introdução}

Com o aumento da população mundial e a necessidade de elevar a produção de alimentos, fibras e energia, é necessário otimizar o uso dos recursos naturais e de produção. Nesse sentido, a tomada de decisão sobre as atividades a serem executadas nos processos produtivos deve ser ágil e dinâmica, principalmente em áreas com plantios florestais de rápido crescimento. Para auxiliar os produtores nessa tarefa, o uso de informações espaciais, precisas e sinópticas, se torna indispensável (Ruas et al., 2014).

Por outro lado, a detecção de mudanças no meio ambiente, em especial na cobertura do solo e uso da terra, vem se tornando cada vez mais necessária e recorrente. Os dados de sensoriamento remoto se destacam como uma forma eficiente, em termos de custos e benefícios, para a detecção das mudanças na superfície terrestre. Os dados multitemporais são ideais para se monitorar e avaliar as tendências de expansão agrícola e os impactos ambientais decorrentes deste processo em longo prazo, requerendo, para tanto, a comparação espacial de diferentes mapas de cobertura terrestre, em distintos momentos, para se determinar as mudanças no espaço e no tempo (Bakr et al., 2012; Sadeghi et al., 2013).

Tendo em vista essas preocupações, percebeu-se que, nos últimos anos, o estado de Goiás passou a apresentar áreas expressivas com plantios florestais, devido, sobretudo, a suas características edafoclimáticas, que facilitam o desenvolvimento de algumas espécies (Reis et al., 2015). Entretanto, a falta de informações sobre este setor dificulta a criação de projetos de pesquisa voltados para áreas estratégicas da silvicultura e, até mesmo, na definição de políticas públicas para o planejamento florestal em âmbito estadual (Morales et al., 2012).

Assim, conhecer a realidade das florestas permite analisar as inter-relações da atividade florestal com de outras áreas, resultando em uma melhor compreensão e aproveitamento do solo e possível redução dos danos ao meio ambiente (Matos et al., 1993).

Por outro lado, a dinâmica dos plantios florestais exige atualizações constantes de cadastros e dos mapas florestais, sendo necessário compreender seus arranjos e os locais em que estão inseridas as áreas de plantios no estado. Essas informações ajudam na tomada de decisão acerca dos recursos florestais, nas perspectivas futuras do setor e nas estratégias gerenciais para atender aos objetivos dos empreendimentos de base florestal (Poggiani et al., 1998; Souza et al., 2007).
O sensoriamento remoto já é reconhecido como uma das ferramentas que auxiliam a compreensão da dinâmica florestal (Moreira \& Rudorff, 2002; Ponzoni et al., 2012), sendo possível gerar informações sobre a estimativa de área plantada, produção agrícola, entre outros. Souza et al. (2007) explicam que essas técnicas podem apresentar alternativas e subsídios para a sistematização de informações advindas de diferentes fontes, tornando possível a integração de dados, o monitoramento e sua atualização de forma eficiente, rápida e de baixo custo.

Vários trabalhos demonstram a eficiência dessas ferramentas em diversas áreas, como o estudo de Malavasi et al. (2013), que quantificaram as mudanças de paisagem durante um período de 50 anos, com ênfase nos tipos de cobertura de dunas naturais ou de Borro et al. (2014), que propuseram uma metodologia para identificar e mapear lagos, a qual envolveu uma análise de 1987 a 2010, com cenas derivadas dos satélites Landsat 5 e 7, sensores TM e ETM, a fim de caracterizar as áreas e entender sua dinâmica, fornecendo um banco de dados robusto de lagos e áreas inundadas, juntamente com seu comportamento temporal, para estabelecer futuros programas de monitoramento.

Bakr et al. (2012) realizaram avaliações, monitoramento e mapeamento de áreas propensas à desertificação no Egito. Por sua vez, Song et al. (2002) estudaram modelos de reflectância de copa geométricaóptica e radiativa (GORT) com o modelo de dinâmica de ecossistemas florestais, para estudar a manifestação da sucessão florestal em imagens ópticas. Maselli (2004) trabalhou com a utilização de imagens dos satélites NOAA-AVHRR e Landsat-TM/ETM+ para produzir séries de dados sobre o índice de vegetação (NDVI) de longo prazo, caracterizando coníferas e espécies florestais de folhas largas em uma área costeira protegida na Itália.

Outras áreas de estudo incluem o monitoramento de desastres ambientais (Lee, 2005; Pradhan \& Youssef, 2010), levantamento e monitoramento de recursos hídricos (Pradhan, 2009; Hu et al., 2013; Lee et al., 2015), serviços ecossistêmicos (Wang et al., 2015), mapeamento e classificação de imagens (Demir et al., 2011; Zhong \& Zhang, 2012), desmatamentos (Asner et al., 2005; Achard et al., 2014; Devries et al., 2016) e inventários florestais (Mcdermid et al., 2009; Gao et al., 2013; Yadav \& Nandy, 2015). 
No Brasil, podemos destacar alguns trabalhos, como o de Almeida \& Vieira (2008), que avaliaram a dinâmica da cobertura vegetal e uso da terra; Sano et al. (2007a), que mapearam a cobertura e o uso do solo no Bioma Cerrado; Prado et al. (2012), que trabalharam com a expansão da fronteira agrícola e mudança no uso do solo, e o de Lopes (2013), que analisou a expansão da silvicultura no Bioma Cerrado.

O uso de imagens de satélite em estudos multitemporais é, portanto, essencial para a classificação do uso e da cobertura do solo de grandes áreas, em escalas regionais e globais (Carrão et al., 2008). Com o aumento dos níveis de extração de recursos naturais no Brasil, particularmente na expansão da economia embasada na exportação de commodities agrícolas, uma parcela crescente do território brasileiro está sendo utilizada para plantações industriais, incluindo árvores, agrocombustíveis e soja, havendo a crescente necessidade de se monitorar e estudar em escalas regionais a rápida expansão de plantações florestais de curto prazo, como as de eucalipto (Kröger, 2012; Maire et al., 2014)

O objetivo desse estudo foi identificar e mapear áreas com silvicultura em Goiás, subdividindo-as pelas mesorregiões do estado. A abordagem envolveu a elaboração de mapas de uso do solo das mesorregiões goianas, para o ano de 2015, derivadas de imagens do satélite Landsat-8 OLI. Também foi realizada a comparação com outros mapas, obtidos por outros autores, projetos e períodos de análise, para se verificar o avanço ou o retrocesso das áreas com silvicultura na área de estudo.

\section{Material e métodos}

O estado de Goiás, localizado no Centro-Oeste do Brasil, possui $340.110,38 \mathrm{~km}^{2}$, dividido em cinco mesorregiões: Centro, Leste, Noroeste, Norte e Sul Goiano (Figura 1). Estende-se entre os paralelos $12^{\circ}$ e $20^{\circ} \mathrm{S}$ e os meridianos $45^{\circ}$ e $54^{\circ} \mathrm{W}$, com altitudes variando entre $182 \mathrm{~m}$ e $1.600 \mathrm{~m}$ (IBGE, 2010; Goiás, 2014).

O clima apresenta um período chuvoso, com altos índices pluviométricos (de outubro a abril), com variação de 1.100 a $2.100 \mathrm{~mm}$, e outro seco, com baixos índices pluviométricos (de maio a setembro), com variação de 20 a 200 mm (Gomes et al., 2016). Os relevos são relativamente planos a levemente ondulados (baixa declividade), sobretudo quando coincidentes com as planícies sedimentares, predominando os solos do tipo latossolos, com fertilidade natural variável de baixa a alta, dependendo do tipo de relevo e da rocha matriz (Carvalho \& Bayer, 2008; Goiás, 2014).
Figura 1. Estado de Goiás e mesorregiões goianas.

Fonte: IBGE (2010).

Figure 1. State of Goiás and its mesoregions.

Source: IBGE (2010).

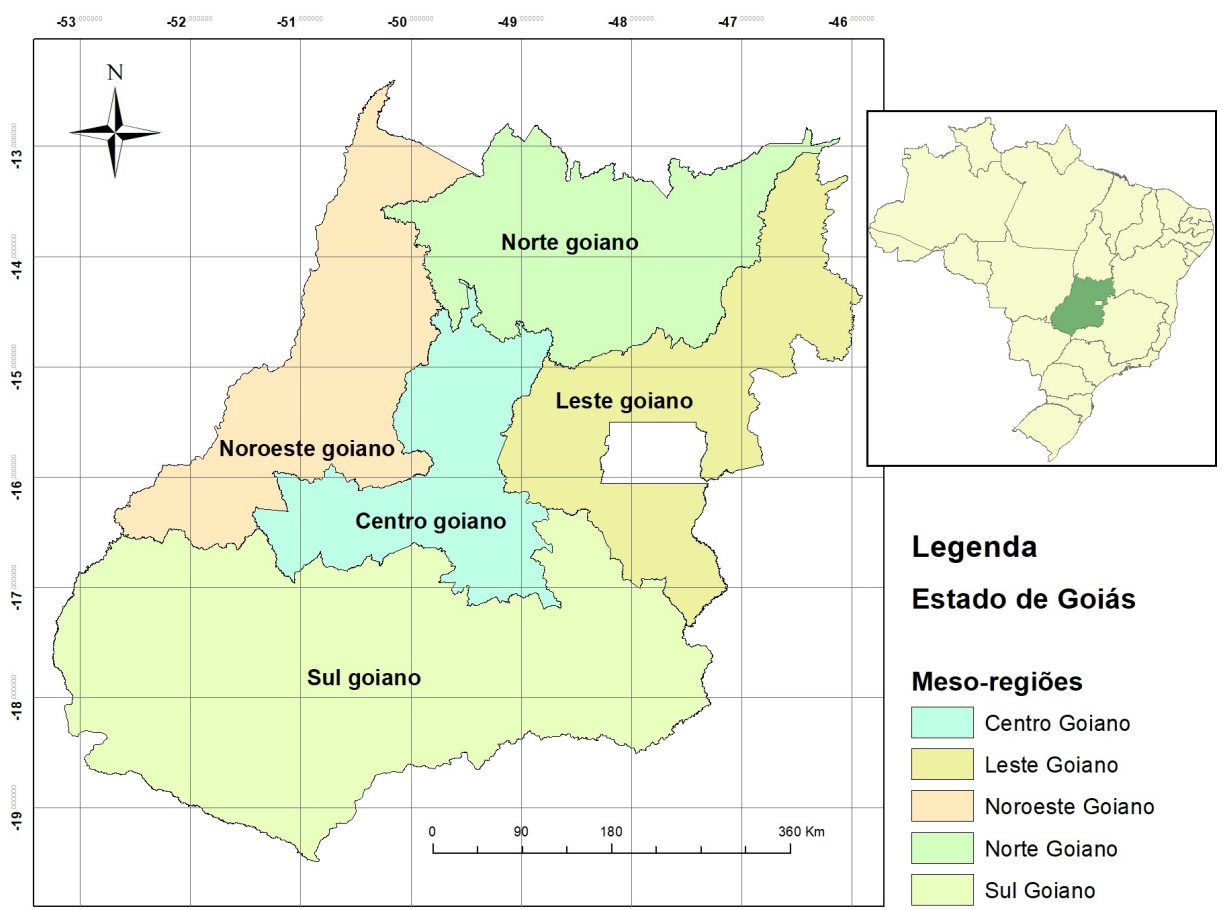




\section{Levantamento de dados}

Os mapas de geomorfologia e solos analisados neste artigo, foram obtidos no Sistema de Geoinformações do estado de Goiás (SIEG), um portal público e gratuito mantido atualmente pelo Instituto Mauro Borges de Estatísticas e Estudos Socioeconômicos (2013) com apoio de outras autarquias estaduais.

A coleta dos dados consistiu na obtenção das cenas do sensor multiespectral Operational Land Imager (OLI), a bordo do satélite Landsat-8, para o ano de 2015. Estas cenas foram empregadas para realização de um novo mapa de uso do solo para Goiás, ressaltando as áreas com plantios florestais, com vistas a uma comparação com as áreas identificadas pelo Projeto de Conservação e Utilização Sustentável da Diversidade Biológica Brasileira (Probio) realizado em 2002 (Brasil, 2002) e pelo Projeto TerraClass Cerrado (realizado em 2013), ambos sob coordenação do Ministério do Meio Ambiente. Os mapeamentos do Probio e TerraClass Cerrado foram obtidos no portal de dados do Laboratório de Processamento de Imagens e Geoprocessamento (Lapig), da Universidade Federal de Goiás.

As imagens de satélite foram obtidas no portal do (USGS, 2016), optando-se por cenas ortorretificadas, com nível de correção Standard Terrain Correction (Level 1T), as quais são produtos pré-processados, apresentando calibração dos números digitais (ND) e valores de reflectância referentes ao topo da atmosfera. Os arquivos vetores (formato shapefiles), com as divisas territoriais do estado de Goiás e dos seus limites municipais e mesorregiões, foram obtidos no portal do IBGE.

A escolha das imagens Landsat levou em consideração os trabalhos realizados no bioma Cerrado por Sano et al. (2007a, 2007b), onde demonstram que, em áreas extensas e com elevada dinâmica em termos de sazonalidade climática, o Landsat-8 é bastante adequado para mapear a cobertura vegetal e antrópica, com resolução espacial e temporal de $30 \mathrm{~m}$ e 16 dias, respectivamente.

A comparação entre os mapeamentos se deu pelos ciclos de corte das florestas, que apresenta uma média de seis anos (ex. eucalipto, que pode ser cortado a partir de 05 anos em algumas regiões de Goiás).

$\mathrm{O}$ avanço das áreas de silvicultura foi identificado pela intersecção das áreas de plantio para 2015, com os mapas de uso da terra oriundos do Probio e do TerraClass Cerrado, visando uma melhor classificação das áreas com plantios florestais no estado de Goiás.
Esta identificação foi realizada com imagens do período seco (de abril a junho) e com a cobertura de nuvens de até $10 \%$. Escolheu-se a estação seca, conforme Sousa \& Ferreira (2014), controlando-se o efeito da sazonalidade sobre os alvos.

A metodologia utilizada no mapeamento de uso do solo do Probio foi feita pelo sistema de classificação do IBGE, descrito no Manual técnico da vegetação brasileira (IBGE, 1992), o qual explica que, nas áreas de reflorestamento e/ou florestamento, é quase impossível de se identificar a espécie utilizada, mesmo em se tratando de grupos bem diferentes, como por exemplo Eucalyptus e Pinus. Portanto, o projeto Probio não faz a discriminação das espécies contidas nas áreas com florestas plantadas e, em alguns casos, as mesmas podem até ser confundidas com culturas perenes de porte arbóreo.

No projeto TerraClass Cerrado, o mapeamento da agricultura anual refere-se às áreas de monocultura, geralmente de ciclo anual, sobretudo de grãos; agricultura perene são áreas extensas, compostas por cultivo de única espécie, com ciclo vegetativo de longa duração, permitindo colheitas sucessivas, sem a necessidade de novos plantios após a colheita; as áreas naturais ou naturais não vegetadas apresentam padrões de cobertura da terra compatíveis com as diferentes fitofisionomias que compõem o bioma Cerrado; pastagem são áreas formadas, prioritariamente, por plantas de forragens exóticas perenes, sendo coberto por vegetação de gramíneas e/ou leguminosas, e as áreas de silvicultura são caracterizadas pelo plantio de uma única espécie florestal, com talhões bem definidos, espaçamentos regulares e da mesma idade (Brasil, 2015). O TerraClass Cerrado também não traz distinção das espécies dentro da classe Silvicultura.

\section{Processamento de dados}

As imagens foram processadas utilizando os softwares $\mathrm{ArcGis}^{\circledR}$ e ENVI ${ }^{\circledR}$, com sistema de projeção e coordenadas geográficas, datum Sirgas 2000, o que permitiu a montagem de um mosaico formado por 24 imagens do Landsat-8, cobrindo todo o estado de Goiás.

Após a montagem dos mosaicos e composições coloridas das imagens, foram realizados os recortes para as mesorregiões do estado. As bandas utilizadas na composição colorida foram selecionadas de acordo com os comprimentos de onda dos alvos mapeados (áreas agrícolas/florestas), possibilitando fazer a análise de 
alvos específicos, como a presença de corpos d'água, diferentes tipos de vegetação e solos.

Assim, para identificar os alvos, foram utilizadas as composições de falsa-cor RGB SWIR/NIR/RED, respectivamente, bandas estas numeradas como 06 (infravermelho de ondas curtas), 05 (infravermelho próximo), 04 (vermelho) do Landsat- 8 , nesta ordem. Os alvos foram separados por classes temáticas: agricultura, água, pastagem, silvicultura, solo exposto e vegetação nativa.

Segundo Luz et al. (2018), pela definição da Food and Agriculture organization of the United Nations (FAO), as classes de uso do solo são separadas por critérios, onde áreas com agricultura e pastagens devem apresentar resquícios de produção de alimentos/fibras e commodities do agronegócio, podendo ser constituída por culturas temporárias, cíclicas e permanentes, como no caso de lavouras semipermanentes e plantios lenhosos perenes (pomares de frutíferas).

As áreas com água são compostas pelo oceano, rios, lagos, lagoas, barragens, represas, canais naturais ou artificiais, tanques d'água, com área igual ou superior a um hectare. Áreas com silvicultura/florestas plantadas são definidas como plantios ou formações de maciços com espécies florestais nativas ou exóticas, puros ou consorciados, não sendo considerado se o plantio é realizado em áreas anteriormente povoadas com espécies florestais ou não; ainda se considera reflorestamento todas as áreas povoadas com essências florestais, independentemente do ambiente, incluindo estradas florestais, barreiras de proteção contra incêndios e quebra-ventos (Luz et al., 2018).

Segundo Luz et al. (2018), são considerada áreas com floresta nativa aquelas que apresentam mais de 0,5 ha, ocupadas por árvores com mais de $5 \mathrm{~m}$ de altura, com uma cobertura de copa maior que $10 \%$, ou árvores capazes de atingir estes limiares in situ, de origem natural, podendo ser definidas tanto pela presença de árvores quanto pela ausência de outros usos da terra predominantes, enquanto que as áreas com solo exposto são definidas como sem cobertura vegetal, devido à influência antrópica, podendo estar ocupadas por atividades de mineração, exploração de jazidas, lavras, bem como áreas de extração de areia. Na Tabela 1 são apresentados exemplos dos alvos selecionados conforme as descrições anteriores, para coleta de amostras utilizadas na classificação supervisionada dos mapeamentos.

A classificação das imagens foi realizada pelo classificador Maximum Likelihood (Maxver), uma técnica de classificação supervisionada que se baseia no modelo estatístico de "máxima verossimilhança". A eficácia do Maxver depende da precisão das amostras coletadas nas imagens/mosaicos (i.e., baseando-se na estimativa do vetor médio e da matriz de covariância de toda classe espectral). O resultado do Maxver é tanto melhor quanto maior o número de pixels selecionados para a parametrização do algoritmo, reduzindo assim os efeitos de sobreposição no processo de classificação e permitindo um trabalho estatístico mais eficiente, com um resultado mais próximo da realidade (Shiba et al., 2005; Cruz \& Ribeiro, 2008).

A seleção dos pixels amostrais foi realizada por meio de análise visual da composição colorida. Após a determinação das amostras, foram tabulados os respectivos valores de máximo, mínimo, média e desvio padrão, para cada classe de cobertura a ser gerada (Tabela 2).

Após as classificações dos mosaicos Landsat, realizou-se a validação dos mesmos (i.e., dos mapas temáticos), a partir da análise da matriz de erro (erros de comissão e omissão) e do índice Kappa (K), o qual indica, numa escala de 0 (zero; classificação péssima) a 1 (classificação excelente), a proximidade de determinada medida no mapeamento com a verdade terrestre, no caso, em relação aos pixels selecionados como amostras de treinamento.

A correção dos erros do mapeamento foi tarefa crucial para a precisão deste, pois os plantios florestais eventualmente são confundidos (nas imagens de satélite) com algumas culturas não florestais, dependendo da época, caso da cafeicultura, canavicultura, citricultura e heveicultura, elencadas por Castro et al. (2014) como as principais culturas produzidas em Goiás. O processo de validação do mapa (2015) foi realizado por visita a campo, empregando um receptor GNSS/GPS portátil. Adicionalmente, foi realizada a seleção de alguns pontos no mapa de classificação, buscando-se o seu posicionamento nas imagens da plataforma Google Earth (2016). 
Tabela 1. Exemplo de chave de classificação utilizada para o mapeamento do uso e cobertura do solo no estado de Goiás.

Table 1. Example of classification key used for the mapping of land use and land cover in Goiás State.

\begin{tabular}{|c|c|c|}
\hline Classes & Padrões de interpretação & $\begin{array}{c}\text { Composição colorida } \\
\text { RGB/654 }\end{array}$ \\
\hline Agricultura & $\begin{array}{l}\text { Padrão de cor: verde-claro } \\
\text { Textura: intermediária } \\
\text { Forma geométrica: regular }\end{array}$ & \\
\hline Água & $\begin{array}{l}\text { Padrão de cor: preto; tons } \\
\text { de azul } \\
\text { Textura: lisa } \\
\text { Forma geométrica: regular }\end{array}$ & \\
\hline Pastagem & $\begin{array}{l}\text { Padrão de cor: verde-claro } \\
\text { Textura: intermediária a lisa } \\
\text { Forma geométrica: regular }\end{array}$ & \\
\hline Silvicultura & $\begin{array}{l}\text { Padrão de cor: verde-claro } \\
\text { Textura: lisa } \\
\text { Forma geométrica: regular }\end{array}$ & \\
\hline $\begin{array}{c}\text { Solo } \\
\text { exposto }\end{array}$ & $\begin{array}{l}\text { Padrão de cor: róseo ou } \\
\text { esbranquiçado } \\
\text { Textura: lisa } \\
\text { Forma geométrica: regular }\end{array}$ & \\
\hline $\begin{array}{l}\text { Vegetação } \\
\text { nativa }\end{array}$ & $\begin{array}{l}\text { Padrão de cor: tons de verde } \\
\text { intercalados } \\
\text { Textura: intermediária e } \\
\text { áspera } \\
\text { Forma geométrica: irregular }\end{array}$ & \\
\hline
\end{tabular}

Tabela 2. Estatística descritiva das amostras de pixels para classificação dos mosaicos.

Table 2. Descriptive statistics of the pixels samples for the mosaics classification.

\begin{tabular}{|c|c|c|c|c|c|c|c|}
\hline & Banda & Água & $\begin{array}{c}\text { Vegetação } \\
\text { nativa }\end{array}$ & Silvicultura & Agricultura & Pastagem & $\begin{array}{c}\text { Solo } \\
\text { exposto }\end{array}$ \\
\hline \multirow{3}{*}{ 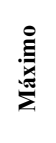 } & Red & 24 & 171 & 144 & 199 & 245 & 215 \\
\hline & Green & 26 & 182 & 251 & 247 & 230 & 204 \\
\hline & Blue & 70 & 97 & 57 & 137 & 236 & 174 \\
\hline \multirow{3}{*}{ 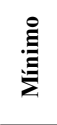 } & Red & 0 & 134 & 112 & 166 & 203 & 194 \\
\hline & Green & 0 & 164 & 217 & 196 & 170 & 188 \\
\hline & Blue & 43 & 33 & 1 & 93 & 144 & 137 \\
\hline \multirow{3}{*}{ 祸 } & Red & 10 & 151 & 123 & 175 & 219 & 199 \\
\hline & Green & 11 & 170 & 229 & 220 & 206 & 197 \\
\hline & Blue & 52 & 62 & 39 & 114 & 191 & 159 \\
\hline \multirow{3}{*}{ 裉 } & Red & 4,8 & 6 & 6,4 & 5,5 & 8,4 & 4 \\
\hline & Green & 5,2 & 3,5 & 5,6 & 10 & 11 & 3,2 \\
\hline & Blue & 4,5 & 13 & 9,3 & 8,8 & 17,4 & 6,8 \\
\hline
\end{tabular}

\section{Resultados}

Na Tabela 3 estão apresentadas as áreas de plantios florestais, considerando todas as culturas florestais plantadas no estado de Goiás, com base em levantamentos censitários realizados pela Indústria Brasileira de Árvores (Ibá, 2016), desde o ano de 2005, seguido pelo avanço/redução das áreas com relação ao ano anterior, assim como os percentuais de representação que as áreas ocupam no estado e seu percentual de crescimento.

Tabela 3. Área com floresta plantada no estado de Goiás, de 2005 até 2015.

Table 3. Area with forest plantation in the State of Goiás, from 2005 to 2015 .

\begin{tabular}{lcccc}
\hline Ano & Área (ha) & $\begin{array}{c}\text { Avanço/ } \\
\text { Redução } \\
\text { (ha) }\end{array}$ & $\begin{array}{c}\text { Percentual } \\
\text { de área de } \\
\text { GO (\%) }\end{array}$ & $\begin{array}{c}\text { Crescimento } \\
\text { (\%) }\end{array}$ \\
\hline $\mathbf{2 0 0 5}$ & 60.872 & - & 0,18 & - \\
$\mathbf{2 0 0 6}$ & 123.174 & 62.302 & 0,36 & 18,31 \\
$\mathbf{2 0 0 7}$ & 115.860 & -7.314 & 0,34 & $-2,15$ \\
$\mathbf{2 0 0 8}$ & 128.377 & 12.517 & 0,38 & 3,68 \\
$\mathbf{2 0 0 9}$ & 130.486 & 2.109 & 0,38 & 0,62 \\
$\mathbf{2 0 1 0}$ & 128.599 & -1.887 & 0,38 & $-0,55$ \\
$\mathbf{2 0 1 1}$ & 129.396 & 797 & 0,38 & 0,23 \\
$\mathbf{2 0 1 2}$ & 131.999 & 2.603 & 0,39 & 0,76 \\
$\mathbf{2 0 1 3}$ & 130.526 & -1.473 & 0,38 & $-0,43$ \\
$\mathbf{2 0 1 4}$ & 133.384 & 2.858 & 0,39 & 0,84 \\
$\mathbf{2 0 1 5}$ & 135.770 & 2.386 & 0,40 & 0,70 \\
\hline
\end{tabular}

Fonte: Ibá, 2016 
Em 2007, Goiás apresentou uma redução de áreas plantadas de aproximadamente 2,15\% em relação a 2006. No ano seguinte, as áreas com plantios representaram $3,68 \%$ de aumento, passando de 115.860 ha para 128.377 ha. Em 2010, tais áreas voltaram a sofrer redução de
0,55\%. A partir de 2014, as áreas com plantios florestais atingiram 133.384 ha, um aumento de $0,38 \%$ com relação à área em 2013, expansão que continuou em 2015, com uma área total plantada de 135.770 ha.

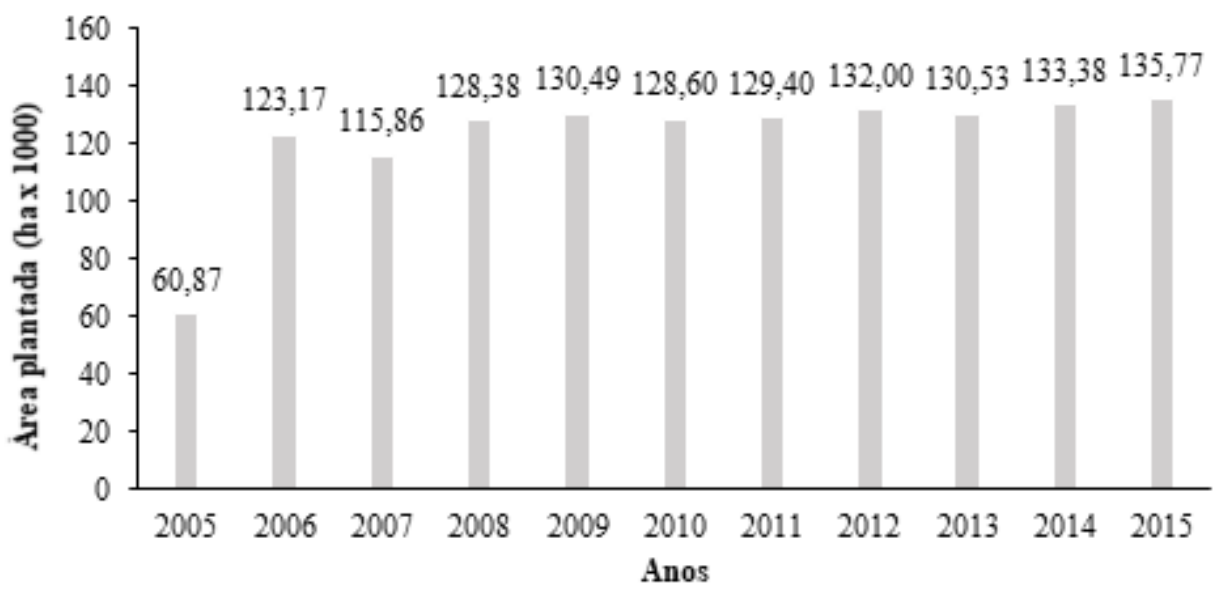

Figura 2. Área com floresta plantada no esstado de Goiás, entre 2005 e 2015.

Figure 2. Area with forest planted in Goiás State, from 2005 to 2015.

Na Tabela 4 observam-se as áreas de plantios florestais mapeadas para as mesorregiões de Goiás, com base nas metodologias apresentadas nesta pesquisa. Segundo Probio (Brasil, 2002), as mesorregiões goianas que apresentaram maior área de florestas plantadas foram a Norte, com aproximadamente $0,29 \%$ de sua área total, e a Sul, com $0,24 \%$ de sua área total, totalizando em as mesorregiões 50.425,52 ha com plantios florestais.

Segundo levantamento realizado pelo projeto TerraClass Cerrado (2013), a área total em Goiás com florestas em 2013 era de 153.142,07 ha, aproximadamente $0,46 \%$ do território goiano. Nesse mapeamento, perceber-se uma melhor participação das mesorregiões dentro do setor florestal, realizado 11 anos após o mapeamento do Probio (Brasil, 2002), ou o equivalente a dois ciclos de corte para florestas de crescimento rápido, como o eucalipto, com uma área bastante expressiva de florestas plantadas. Em 2013, a mesorregião Centrogoiano aparece com $0,54 \%$ de área plantada, aumento de $0,50 \%$ com relação a 2002. A mesorregião Leste apresenta uma área de 29.695,55 ha, com um aumento de 0,46\% em relação a 2002, assim como as mesorregiões Norte, com aumento de $0,20 \%$, e a Sul, com aumento de $0,45 \%$ das áreas em relação a 2002. Importante frisar que a mesorregião Sul possui a maior área com florestas plantadas em Goiás (82.733,21 ha), seguida pela mesorregião Leste $(29.695,55 \mathrm{ha})$.

Em 2015, com base no mapeamento satelitário gerado nesta pesquisa, foram registrados $162 \mathrm{mil} \mathrm{ha}$ com florestas plantadas em Goiás $(0,48 \%$ do território goiano). No intervalo de dois anos (2013 - 2015), as mesorregiões Centro e Leste apresentaram pequenos decréscimos nas áreas plantadas, de $0,07 \%$ e $0,06 \%$, respectivamente, enquanto as mesorregiões Norte e Sul apresentaram ampliação das áreas plantadas, em 0,04\% e $0,05 \%$, sendo que, ao todo, Goiás apresentou aumento de aproximadamente 9 mil ha com florestas comerciais (em relação a 2013), concentrados nas mesorregiões Sul e Leste.

As divergências entre as áreas totais apresentadas pelos três mapeamentos ocorrem porque os mapas dos projetos Probio e TerraClass Cerrado abrangem todo o bioma Cerrado, em todas as federações, com metodologias de classificação diferentes das utilizadas nesse trabalho. Ressalta-se que dentro do estado de Goiás, aproximadamente 3\% (ou $9 \mathrm{mil} \mathrm{km}^{2}$ ) da 
vegetação é pertencente ao bioma Mata Atlântica, não tendo sido mapeados pelos projetos Probio (Brasil, 2002) e TerraClass (2013).

É válido também mencionar que trabalhos de campo específicos para esta pesquisa foram realizados, de forma a garantir a confiabilidade dos resultados, uma vez que o Coeficiente Kappa obtido na validação do mapeamento automatizado foi de 0,79 .

Pela análise dos mapas da mesorregião Centro-Oeste goiano, para os três mapeamentos (2002, 2013 e 2015), nota-se que os 10 municípios com plantios florestais comerciais mais expressivos foram: Goiânia, Anápolis, Ceres, Bela Vista de Goiás, Itapuranga, Anicuns, Iporá, Cachoeira de Goiás, Campo Lindo de Goiás e Ouro Verde de Goiás.

Em 2002, 60,5\% da mesorregião Centro-Oeste era composta por pastagens, seguido por $13 \%$ com agricultura. No mapeamento realizado em 2013, percebe-se uma redução nessas classes, sendo que a pastagem passou a representar $57 \%$ e a agricultura apenas 7,61\%. Em contrapartida, ainda em 2013, as áreas com remanescentes de vegetação nativa tiveram um aumento de quase $8 \%$ (de $24,23 \%$ para $32 \%$ ) e em 2015, a área de pastagem manteve-se praticamente igual, com 57,78\% dessa mesorregião $(2.356 .908,38$ ha), ocorrendo o mesmo com a agricultura $(7,86 \%)$, registrando-se um aumento aproximado de $0,54 \%$ e $0,25 \%$, respectivamente.

Seguindo a mesma lógica de análise para a mesorregião Leste, nesta os municípios que mais se destacaram com os plantios de floresta comercial em 2015 foram: Luziânia, Abadiânia, Cristalina, Alexânia, Água Fria de Goiás, Formosa, Corumbá de Goiás, Cidade Ocidental, Padre Bernardo e Pirenópolis. A área com agricultura foi de $636.901,48$ ha, com aumento de $0,46 \%$ em relação a 2013. A área com pastagem obteve $0,18 \%$ de expansão, totalizando $14.278,72$ ha. As áreas com remanescentes de vegetação nativa reduziram em $0,95 \%$.

Tabela 4. Área de florestas plantadas no estado de Goiás, mapeadas em diferentes momentos/projetos.

Table 4. Area of forests planted in Goiás State, mapped in different moments/projects.

\begin{tabular}{|c|c|c|c|c|}
\hline Projeto & Mesorregião & Área mapeada $\left(\mathrm{Km}^{2}\right)$ & $\begin{array}{c}\text { Área de floresta plantada } \\
\text { (ha) }\end{array}$ & $\begin{array}{c}\text { Percentual em área } \\
(\%)\end{array}$ \\
\hline \multirow{6}{*}{$\begin{array}{l}\text { Probio (Brasil, } \\
\text { 2002) }\end{array}$} & Centro & $40.788,779$ & $1.696,477$ & 0,04 \\
\hline & Leste & $55.678,688$ & $3.909,605$ & 0,07 \\
\hline & Noroeste & $55.606,201$ & 0,000 & 0,00 \\
\hline & Norte & $56.590,280$ & $16.174,042$ & 0,29 \\
\hline & Sul & $121.128,021$ & $28.645,395$ & 0,24 \\
\hline & Total & $329.791,970$ & $50.425,519$ & 0,15 \\
\hline \multirow{6}{*}{$\begin{array}{c}\text { TerraClass Cerrado } \\
\text { (2013) }\end{array}$} & Centro & $40.788,865$ & $22.204,039$ & 0,54 \\
\hline & Leste & $55.680,417$ & $29.695,557$ & 0,53 \\
\hline & Noroeste & $55.606,135$ & $1.308,865$ & 0,02 \\
\hline & Norte & $56.591,632$ & $17.200,406$ & 0,30 \\
\hline & Sul & $121.171,469$ & $82.733,212$ & 0,68 \\
\hline & Total & $329.838,520$ & $153.142,078$ & 0,46 \\
\hline \multirow{6}{*}{$\begin{array}{c}\text { Área mapeada } \\
2015\end{array}$} & Centro & $40.177,263$ & $19.023,810$ & 0,47 \\
\hline & Leste & $57.899,076$ & $27.404,445$ & 0,47 \\
\hline & Noroeste & $54.530,784$ & $1.219,841$ & 0,02 \\
\hline & Norte & $55.121,256$ & $19.140,110$ & 0,35 \\
\hline & Sul & $130.816,262$ & $95.728,484$ & 0,73 \\
\hline & Total & $338.544,641$ & $162.516,690$ & 0,48 \\
\hline
\end{tabular}


A mesorregião Noroeste é a que menos apresenta áreas com florestas comerciais plantadas, sendo os municípios produtores: São Miguel do Araguaia, Faina, Mozarlândia, Novo Planalto e Goiás. A área com plantios florestais em 2015 foi de 1.219,84 ha, ou aproximadamente $0,20 \%$ da mesorregião.

Em 2015, a área de pastagem nesta mesorregião era de 3.209.463,79 ha (57,72\% da área); em 2013, a área de pastagem era praticamente a mesma, com 57,69\%, enquanto em 2002 esta classe ocupava cerca de 50\% desta mesorregião. Quanto à classe de agricultura, entre 2002 e 2013, esta apresentou redução de 12,95\%, com um pequeno aumento entre 2013 e 2015 , de apenas 0,02\% (totalizando 93.230,78 ha em 2015).

$\mathrm{Na}$ mesorregião Norte goiano, os principais municípios com áreas de florestas plantadas eram, em 2015, Porangatu, Niquelândia, Chapada dos Veadeiros, São João d'Aliança, Alto Paraiso de Goiás, Porangatu, Estrela do Norte, Bonópolis, Campinaçu e Uruaçu.

Em 2002, a área de agricultura no Norte goiano era de 59.928,797 ha, aproximadamente 1,06\% desta mesorregião. Em 2013, essas áreas representavam $2,14 \%$. As áreas de pastagem passaram de $22,90 \%$ para $33,53 \%$, apresentando uma área de 1.897.101,75 ha. A classe de remanescente de vegetação nativa apresentou redução de $12,45 \%$ entre 2002 e 2013 , e redução de $2,28 \%$ entre 2013 e 2015 . Nas áreas de agricultura, em 2015 somaram 133.782,32 ha, com aumento de $0,22 \%$ desde 2013; as áreas de pastagens apresentaram aumento de $2,08 \%$, enquanto os remanescentes de Cerrado apresentaram redução de 2,28\% em relação a 2013.

Os municípios de Catalão, Ipameri, Rio Verde, Pires do Rio, Campo Alegre de Goiás, Chapadão do Céu,
Santa Rita do Araguaia, Mineiros, Quirinópolis e Jataí consistem nos 10 municípios com maior representação de área com plantios florestais dentro da mesorregião Sul.

Nesta mesorregião (Sul), as áreas de pastagens em 2015 representaram $41,32 \%$ da área total, seguido pela agricultura, com $28,57 \%$, e das áreas com remanescentes de Cerrado, com 28,33\%. Com relação à mudança no uso do solo, entre 2002 e 2013, as áreas com pastagens correspondiam a 4.656.181,96 ha $(38,44 \%)$, com aumento de $0,61 \%$ em 2013. As áreas de agricultura ocupavam 27,25\% da área em 2013 (3.301.324,66 ha), com aumento de 1,03\% em relação ao ano de 2002.

Como pode ser observado na Figura 3, grande parte das áreas de florestas plantadas encontrava-se em áreas de Aplainamento II e III, nas mesorregiões CentroOeste e Sul; Aplainamento IV, nas mesorregiões Leste e Noroeste; e algumas áreas plantadas na mesorregião Norte, identificadas em regiões de controle estrutural.

Na Figura 4 pode-se observar que muitos plantios se encontram em áreas com latossolos, cambissolos e argissolos, isso porque esses solos são adequados ao uso de maquinários, devido a características físicas e ao relevo, bem como pela elevada permeabilidade. Ademais, alguns solos são dotados de maior fertilidade química, enquanto outros podem se apresentar como solos rasos. Verifica-se também a presença de plantios em áreas com planossolo (Leste e Sul Goiano) e em áreas com plintossolo (Leste Goiano). 


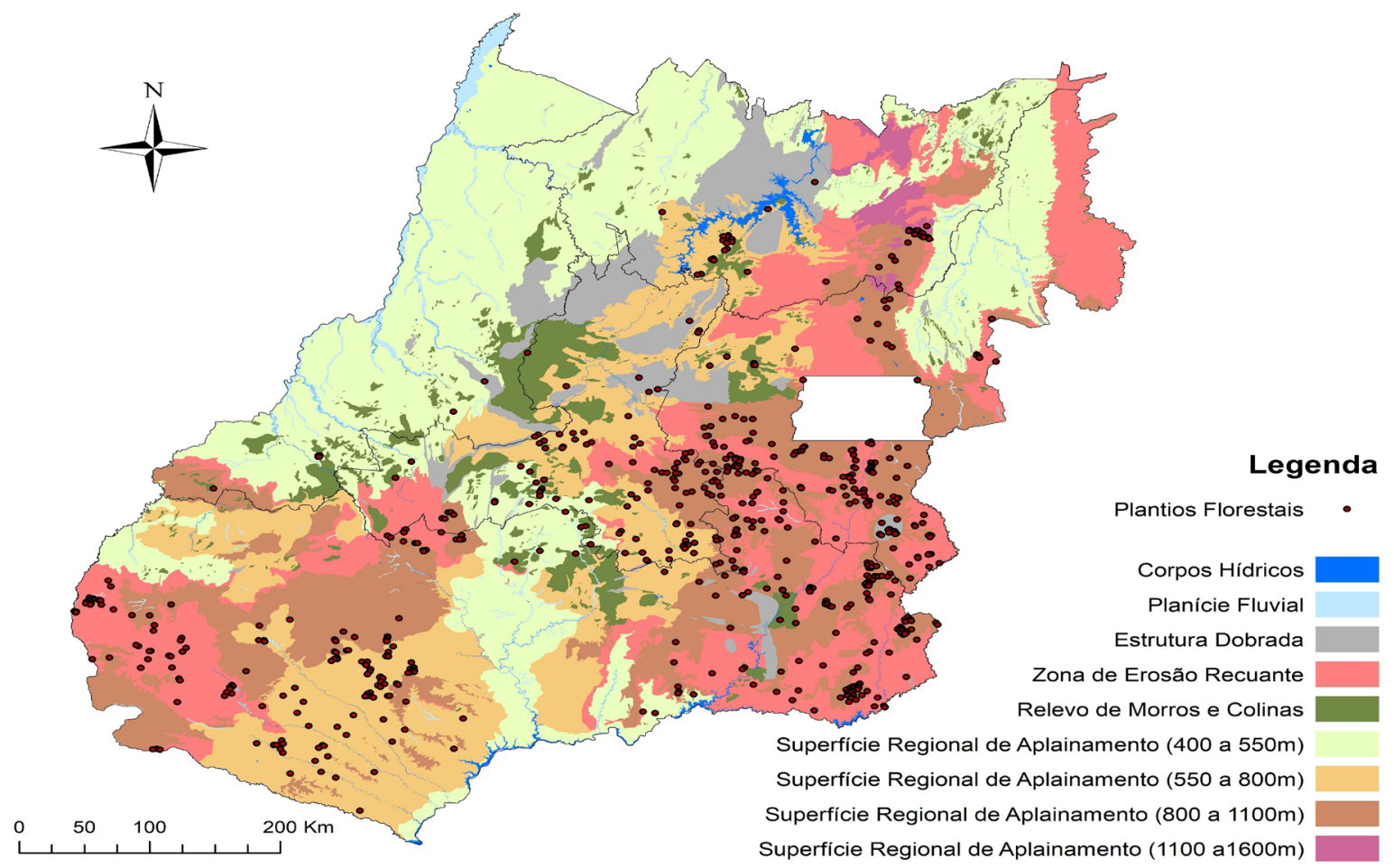

Figura 3. Mapa de geomorfologia do estado de Goiás. Fonte: Goiás (2019).

Figure 3. Geomophology map of Goiás State. Source: Goiás (2019).

Figura 4 Mapa de solos do estado de Goiás. Fonte: (Goiás, 2019).

Figure 4. Soils map of Goiás State. Source: (Goiás, 2019).

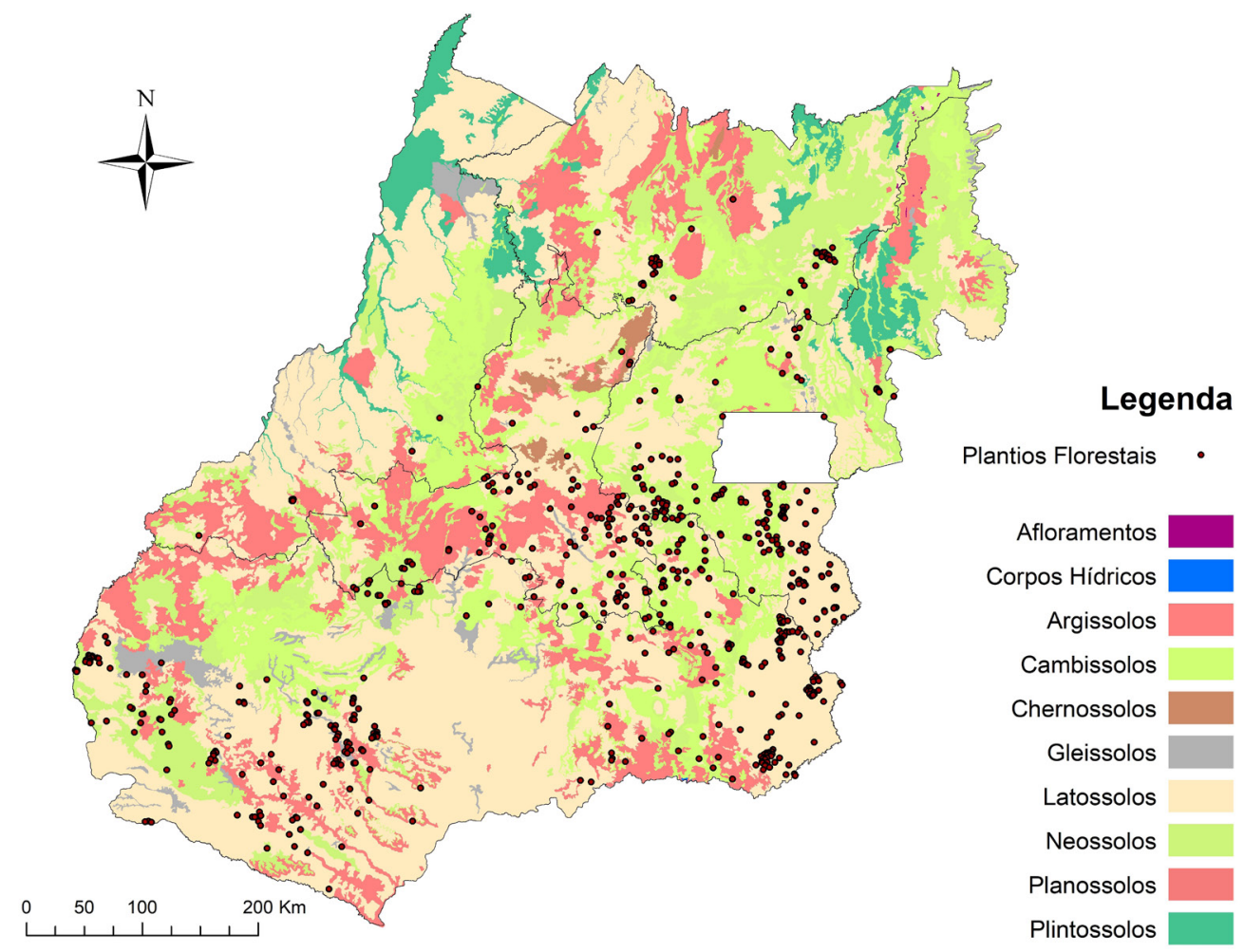




\section{Discussão}

A área com plantios de florestais em Goiás, entre 2005 e 2015, foi marcada por um crescimento absoluto de 75 mil ha ao final de uma década (maior parte composta por plantios de eucalipto), porém com pequenas flutuações de aumento de área ao longo desse período (Tabela 1).

Ao analisar esse conjunto de dados, deve-se considerar que os primeiros dados de área com floresta plantada em Goiás foram divulgados pela Abraf (2006), referentes a 2005, os quais totalizaram uma área de 60.872 ha, sendo 47.542 ha de floresta de eucalipto e 13.330 ha de plantios de Pinus spp. Em 2006, a área plantada era de 64.046 ha, sendo 49.637 ha de eucalipto e 14.409 ha de plantios com Pinus spp. A partir da atualização do banco de dados das áreas plantadas no Brasil, realizado pelo Ibá, o valor de área plantada em Goiás em 2006 subiu para 123.174 ha, um aumento de mais de 62 mil ha.

Ao comparar os dados dos mapeamentos com os dados censitários existentes, observou-se que a Ibá divulgou como resultado de 2013 a existência de 130.526 ha de florestas plantadas em Goiás (Ibá, 2015). Ou seja, 11.864 ha a menos que os dados divulgados pela Produção da Extração Vegetal e da Silvicultura (PEVS) do IBGE no mesmo período, enquanto que no TerraClass Cerrado, a área total plantada foi de 150.142 ha (Tabela 2), ou seja, uma divergência de aproximadamente 17.372 ha em relação aos valores da Ibá.

Em 2015, a área de floresta plantada divulgada pela Ibá foi de 135.770 ha (Ibá, 2016), e pelo IBGE (2015) 143.070 ha, valores inferiores ao encontrado no mapeamento realizado neste trabalho (162.516 ha), ou seja, uma diferença de aproximadamente $0,8 \%$. Desta forma, nota-se que a Ibá tem subestimado algumas áreas de floresta em Goiás.

Foi observado nos dados do IBGE (2013) que, em 2013, 27 municípios, dos 246 que compõem o estado de Goiás, não apresentaram quantificação de áreas com plantios florestais, enquanto em 2015 esse número foi reduzido a 9 municípios. A falta de dados para esses municípios pode ter ocorrido devido à falta de pessoas para conversar com os agentes do IBGE no momento da visita, pois os dados da PEVS são obtidos mediante consulta aos locais e órgãos ligados, direta ou indiretamente, aos setores da produção, comercialização, industrialização e fiscalização de produtos vegetais nativos.
Por estes motivos, nesta pesquisa, os trabalhos de campo foram necessários para validar os resultados, ainda que o Coeficiente Kappa obtido nas classificações tenha atingido 0,79 (i.e., considerada como "muito boa"), numa escala de 0 a 1, conforme explicam Figueiredo \& Vieira (2007).

Dessa forma, leva-se em consideração que o avanço da área plantada com florestas no Brasil, de uma forma geral, deve-se, sobretudo, ao aumento da fronteira florestal de silvicultura para a produção de celulose/ papel e produção de energia, como é o caso do estado de Goiás, onde a maioria dos plantios é destinada à produção energética (lenha, cavacos, briquetes, etc.), e em algumas regiões para a movelaria.

É importante destacar que, em função das significativas oscilações de clima e nos mercados, sobretudo dos preços, a rentabilidade das culturas agrícolas e florestais pode sofrer alteração, levando o produtor a pensar quais culturas são mais rentáveis em curto, médio e longo prazos; ou seja, normalmente o produtor opta por plantar a cultura que fornecer maior receita, em um menor período de tempo.

Prado et al. (2012) explicam que, em alguns casos, a agricultura tende a se expandir sobre as áreas de pastagens, assim como foi observado em seus estudos sobre a mesorregião Sul de Goiás, que, por sua vez, tenderam a ocupar áreas de vegetação nativa. Da mesma forma, as áreas de florestas plantadas também se expandem sobre as áreas de pastagens, sem um ordenamento definido.

Muitos dos plantios se encontram em áreas de Neossolos, e em zonas de erosão recuante, o que pode acarretar baixas taxas de produtividade para os plantios, os quais, ainda que em pequena escala, visam suprir as demandas de madeira para várias finalidades, como bioenergia, serraria e também de borracha.

Carvalho \& Bayer (2008) demostraram que a geomorfologia do estado de Goiás apresenta uma expressiva predominância de formas denudacionais, ou seja, elevada perda de solo por processos erosivos, chegando a ocupar $98 \%$ de sua superfície. Essas formas são identificadas e classificadas nas seguintes categorias: Superfície Regional de Aplainamento (SRA) I (mais antiga), II, III e VI (mais nova), Zona de Erosão Recuante (ZER), Morros e Colinas (MC), Estruturais e Agradação. Esses autores também encontraram consideráveis áreas agrícolas, sobretudo em regiões de SRA II e áreas de pastagens nas SRA III e IV, por apresentarem relevos 
mais instáveis. Desse modo, entende-se que a utilização dessas áreas para o plantio de florestas é interessante, pois, assim como descrito por Prado et al. (2004), o sistema radicular promove a ancoragem física das árvores e propicia a captação de água e nutrientes essenciais ao crescimento vegetal, criando condições para a estabilização dos solos.

Porém, do ponto de vista produtivo e econômico, o uso dessas áreas é inviável para realização de plantios comerciais, por apresentarem fatores químicos e físicos que limitam o crescimento e produtividade dos sítios, como, por exemplo, compactação e declividade que em alguns casos inviabilizam a entrada de maquinário, entre outros fatores que inviabilizariam economicamente o plantio nessas áreas.

Sano et al. (2007a) indicam que 52\% da área do estado é formada pelos Latossolos, 15\% de Argissolos e Nitossolos, $12 \%$ de Cambissolo e 4\% de Plintossolos. Dessa forma, pode-se dizer que Goiás tem potencial para aumentar suas áreas cultiváveis, dentre estas as de florestas plantadas. Por outro lado, ressalta-se também o risco de expansão agrícola com inobservância aos recursos hídricos, fauna e flora, reduzindo ainda mais as áreas com remanescentes de Cerrado (Fernandes et al., 2016). Neste caso, áreas com pastagens degradadas, por exemplo, em terrenos pouco ondulados e com solos mais profundos, poderiam atender a esta expansão.

Gonçalves et al. (2015) explicam que dos plantios florestais presentes no Brasil, aproximadamente 21\% se encontram em áreas de Cerrado, devido à quantidade de chuva, índices térmicos e sazonalidade climática mais adequadas; antes, tais áreas eram de pastagens ou utilizadas com cultivos agrícolas.

Ferreira \& Silva (2008) explicam que, em muitos sítios, a produtividade florestal está aquém do seu potencial biológico, havendo possibilidade de aumento da produtividade em grande escala, pela adoção de técnicas apropriadas de manejo de solo e da plantação. Com isso, atribui-se à geomorfologia e às propriedades do solo o baixo índice de produtividade florestal de algumas áreas.

A grande variabilidade de solos e de topografia reflete a ampla extensão das áreas de plantios e das possibilidades para expansão das florestas comerciais no estado. Porém, de modo geral, os ecossistemas onde está estabelecida a maioria das plantações florestais são sensíveis à perturbação antrópica, devido a diversas razões ecológicas e históricas: condições climáticas, com ocorrências de chuvas de alto poder erosivo; plantações em relevo acidentado; solos de baixa fertilidade natural; plantações em áreas agrícolas com solos degradados, entre outros fatores.

\section{Conclusões}

As mesorregiões em Goiás com as maiores áreas plantadas com florestas comerciais são a Sul, Leste e Norte, sendo que a Sul e a Leste são as maiores produtoras de lenha e madeira em tora nesse estado. Os valores de produção para o Centro-goiano constituem a terceira colocação de produção, porém, esta mesorregião é a quarta colocada em relação às áreas plantadas.

A distribuição espacial dos plantios de eucalipto se caracteriza por sua atomização e por uma produção não verticalizada dos produtores, refletindo o potencial da atividade florestal na geração de renda em pequenas e médias propriedades.

Apesar das diferenças de metodologia entre os mapeamentos avaliados neste estudo, foi possível quantificar o crescimento da produção de florestas plantadas, culminando no mapa de 2015, obtido com imagens do satélite Landsat-8, sensor OLI. Os resultados encontrados estão coerentes com a real condição de plantios no estado de Goiás. Desse modo, destaca-se a importância das técnicas de sensoriamento para o monitoramento do uso do solo, em especial para o setor madeireiro, garantindo também o acesso aos dados espaciais para o público em geral.

Por fim, visando melhorar o detalhamento das áreas plantadas no estado de Goiás, faz-se necessário realizar mais pesquisas sobre o tema, com emprego de novos sensores remotos (em nível orbital e aéreo, com maior resolução espacial), aliado a novas técnicas e metodologias de mapeamento.

\section{Referências}

Anuário estatístico da ABRAF 2006: ano base 2005. Brasília, DF: ABRAF, 2006.

Achard, F. et al. Determination of tropical deforestation rates and related carbon losses from 1990 to 2010. Global Change Biology, v. 20, p. 2540-2554, 2014. https://doi.org/10.1111/gcb.12605.

Almeida, A. S. \& Vieira, I. C. G. Dinâmica da cobertura vegetal e uso da terra no município de São Francisco do Pará (Pará, Brasil) com o uso da técnica de sensoriamento remoto. Boletim do Museu Paraense Emílio Goeldi: Ciências Naturais, v. 3, n. 1, p. 81-92, 2008. 
Asner, G. P. et al. Selective logging in the Brazilian Amazon. Science, v. 310, n. 5747, p. 480-482, 2005. https://doi.org/10.1126/ science.1118051.

Bakr, N. et al. Multi-temporal assessment of land sensitivity to desertification in a fragile agro-ecosystem: environmental indicators. Ecological Indicators, v. 15, p. 271, 2012.

Borro, M. et al. Mapping shallow lakes in a large South American floodplain: a frequency approach on multitemporal Landsat TM/ETM data. Journal of Hydrology, v. 512, p. 39-52, 2014.

Brasil. Ministério do Meio Ambiente. Mapeamento do uso do solo e cobertura do cerrado: Projeto TerraClass Cerrado 2013. Brasília, DF, 2015.

Brasil. Ministério do Meio Ambiente. Projeto de Conservação e Utilização Sustentável da Biodiversidade Biológica Brasileira: Probio. Cobertura vegetal do Cerrado (2002). Brasília, DF, [2016]. Disponível em: <http://maps.lapig .iesa.ufg.br/lapig.html>. Acesso em: 15 mar. 2016.

Carrão, H. et al. Contribution of multispectral and multitemporal information from MODIS images to land cover classification. Remote Sensing of Environment, v. 112, p. 986-997, 2008. https:// doi.org/10.1016/j.rse.2007.07.002.

Carvalho, T. M. de \& Bayer, M. Utilização dos produtos da "Shuttle Radar Topography Mission" (SRTM) no mapeamento geomorfológico do estado de Goiás. Revista Brasileira de Geomorfologia, n. 1, 2008.

Castro, M. C. et al. Municípios goianos: competitividade e concentração da fruticulture. In: Goiás. Secretaria de Estado de Gestão e Planejamento. Instituto Mauro Borges de Estatísticas e Estudos Socioeconômicos. Conjuntura Econômica Goiana, n. 29, p. 47-63, 2014.

Cruz, Z. Q. \& Ribeiro, G. P. Ensaios de segmentação e classificação digital de imagens CBERS utilizando o sistema Spring em uma unidade de conservação ambiental estudo de caso: Parque Nacional da Serra dos Órgãos (PARNASO). In: SIMPÓSIO BRASILEIRO DE CIÊNCIAS GEODÉSICAS E TECNOLOGIAS DA GEOINFORMAÇÃO, 2., 2008, Recife: UFPE. Anais... Recife: UFPE, 2008.

Demir, B. et al. Batch-mode active-learning methods for the interactive classification of remote sensing images. IEEE Transactions on Geoscience and Remote Sensing, v. 49, n. 3, p. 1014-1031, 2011. https://doi.org/10.1109/TGRS.2010.2072929.

Devries, B. et al. Characterizing forest change using communitybased monitoring data and landsat time series. PLoS One, v. 11, n. 3, 2016. https://doi.org/10.1371/journal.pone.0147121.

Fernandes, G. W. et al. Afforestation of savannas: an impending ecological disaster. Natureza \& Conservação, v. 14, n. 2, p. 146151, 2016. https://doi.org/10.1016/j.ncon.2016.08.002.

Ferreira, C. A. \& Silva, H. D. As plantações florestais. In: Ferreira, C. A. \& Silva, H. D. (Orgs.) Formação de povoamentos florestais. Colombo: Embrapa Florestas, 2008. p. 33-41.
Figueiredo, G. C. \& Vieira, C. A. O estudo do comportamento dos índices de Exatidão Global, Kappa e Tau, comumente usados para avaliar a classificação de imagens do sensoriamento remoto. In: SIMPÓSIO BRASILEIRO DE SENSORIAMENTO REMOTO, 13., 2007, Florianópolis. Anais... Florianópolis: INPE, 2007. p. $5755-5762$.

Gao, Y. et al. Estimation of the North-South transect of Eastern China forest biomass using remote sensing and forest inventory data. International Journal of Remote Sensing, v. 34, n. 15, p. 5598-5610, 2013. https://doi.org/10.1080/01431161.2013.794985.

Goiás. Secretaria de Estado de Gestão e Planejamento. Goiás em dados 2014. Goiânia, 2014.

Goiás. Sistema Estadual de Geoinformação. Disponível em: <www.sieg.go.gov.br>. Acesso em: 22 maio 2019.

Goiás. Superintendência de Geologia e Mineração (SGM). Sistema Estadual de Geoinformação do estado de Goiás. Goiânia, 2006. Disponível em: <www.sieg.go.gov.br>. Acesso em: 13 abr. 2015.

Gomes, M. P. et al. Avaliação de imagens MODIS para o monitoramento de desmatamento em áreas de Cerrado do estado de Goiás. Disponível em: < https://www.lapig.iesa.ufg.br/lapig/index. $\mathrm{php} /$ component/jdownloads/send/4-periodicos/292-avaliacao-deimagens-modis-para-o-monitoramento-de-desmatamento-em-areasde-cerrado-do-estado-de-goias?Itemid=0 > . Acesso em: 11 abr. 2016.

Gonçalves, J. L. M. et al. Caracterização edafoclimática e manejo das áreas com plantações de eucalipto. In: Schumacher, M. V. \& Viera, M. (Org.) Silvicultura do eucalipto no Brasil. Santa Maria: Ed. UFSM, 2015. p. 113-155.

Google Earth. Disponível em: <www.google.com/earth/>. Acesso em: 7 mar. 2016.

$\mathrm{Hu}, \mathrm{C}$. et al. Uncertainties of SeaWiFS and MODIS remote sensing reflectance: implications from clear water measurements. Remote Sensing of Environment, v. 133, p. 168-182, 2013. https://doi. org/10.1016/j.rse.2013.02.012.

Ibá. Indústria Brasileira de Árvores. Ibá: Indústria Brasileira de Árvores 2015. Brasília, DF, 2015. 100 p. Relatório Ibá 2015.

Ibá. Indústria Brasileira de Árvores. Ibá: Indústria Brasileira de Árvores 2016. Brasília, DF, 2016. 100 p. Relatório Ibá 2016.

IBGE. Instituto Brasileiro de Geografia e Estatística. Malhas digitais. 2010. Disponível em: <http://mapas.ibge.gov.br/bases-e-referenciais/ bases-cartograficas/malhas-digitais.html>. Acesso em: 14 set. 2015.

IBGE. Instituto Brasileiro de Geografia e Estatísticas. Manual técnico da vegetação brasileira. Rio de Janeiro, 1992. 91 p.

IBGE. Instituto Brasileiro de Geografia e Estatísticas. Produção da extração vegetal e da silvicultura. Rio de Janeiro, [2013]. Disponível em: $<$ https://sidra.ibge.gov.br/tabela/5930>. Acesso em: janeiro de 2019.

IBGE. Instituto Brasileiro de Geografia e Estatísticas. Produção da extração vegetal e da silvicultura. Rio de Janeiro, [2015]. Disponível em: <https://sidra.ibge.gov.br/tabela/5930>. Acesso em: janeiro de 2019. 
Instituto Mauro Borges de Estatísticas e Estudos Socioeconômicos. Sistema Estadual de Geoinformação. Goiânia, 2013. Disponível em: < www.sieg.go.gov.br >. Acesso em: 23 maio 2019.

Kröger, M. The expansion of industrial tree plantations and dispossession in Brazil. Development and Change, v. 43, p. $947-$ 973, 2012. https://doi.org/10.1111/j.1467-7660.2012.01787.x.

Lee, S. Application of logistic regression model and its validation for landslide susceptibility mapping using GIS and remote sensing data. International Journal of Remote Sensing, v. 26, n. 7, p. 1477-1491, 2005. https://doi.org/10.1080/01431160412331331012.

Lee, S. et al. Estimating oceanic primary productivity from ocean color remote sensing: a strategic assessment. Journal of Marine Systems, v. 149, p. 50-59, 2015. https://doi.org/10.1080/0143116 1.2013.794985.

Lopes, C. R. Expansão da silvicultura de eucalipto no bioma cerrado: uma análise sob a perspectiva dos fatores físicos e socioeconômicos. 2013. Dissertação (Mestrado em Agronegócio) - Universidade Federal de Goiás, Goiânia.

Luz, N. B. et al. Manual de análise da paisagem: volume 1: procedimento para a execução do mapeamento de uso e cobertura da terra. Colombo: Embrapa Florestas, 2018.92 p. (Embrapa Florestas. Documentos, 316).

Marie, G. et al. Mapping short-rotation plantations at regional scale using MODIS time series: case of eucalypt plantations in Brazil. Remote Sensing of Environment, v. 152, p. 136-149, 2014. https:// doi.org/10.1016/j.rse.2014.05.015.

Malavasi, M. et al. What has happened to coastal dunes in the last half century? A multitemporal coastal landscape analysis in Central Italy. Landscape and Urban Planning, v. 119, p. 54-63, 2013. https://doi.org/10.1016/j.landurbplan.2013.06.012.

Maselli, F. Monitoring forest conditions in a protected Mediterranean coastal area by the analysis of multiyear NDVI data. Remote Sensing of Environment, v. 89, p. 423-433, 2004. https://doi.org/10.1016/j. rse.2003.10.020.

Matos, F. D. A. et al. Identificação de estratos de reflorestamento de Pinus taeda através de imagens digitais do Landsat-5. In: CONGRESSO FLORESTAL BRASILEIRO, 7., 1993, Curitiba. Anais... São Paulo: SBS/SBEF, 1993. v. 2. p.516-519.

Mcdermid, G. J. et al. Remote sensing and forest inventory for wildlife habitat assessment. Forest Ecology and Management, v. 257, p. 2262-2269, 2009. https://doi.org/10.1016/j.foreco.2009.03.005.

Morales, M. M. et al. Caracterização do setor florestal goiano. Colombo: Embrapa Florestas, 2012. 49 p. (Embrapa Florestas. Documentos, 241). Disponível em: < https://www.infoteca.cnptia. embrapa.br/infoteca/handle/doc/946815>.

Moreira, M. A. \& Rudorff, B. F. T. Sensoriamento remoto aplicado à agricultura. São Jose dos Campos: Inpe, 2002.

Poggiani, F. et al. Indicadores de sustentabilidade das plantações florestais. Série Técnica IPEF, v. 12, n. 31, p. 33-44, 1998.

Ponzoni, F. J. et al. Sensoriamento remoto da vegetação. 2. ed. São Paulo: Oficina de textos, 2012.
Pradhan, B. Groundwater potential zonation for basaltic watersheds using satellite remote sensing data and GIS techniques. Central European Journal of Geosciences, v. 1, n. 1, p. 120-129, 2009. https://doi.org/10.2478/v10085-009-0008-5.

Pradhan, B. \& Youssef, A. M. Manifestation of remote sensing data and GIS on landslide hazard analysis using spatial-based statistical models. Arabian Journal of Geosciences, v. 3, p. 319-326, 2010. https://doi.org/10.1007/s12517-009-0089-2.

Prado, L. A. et al. Expansão da fronteira agrícola e mudanças no uso do solo na região sul de Goiás: Ação antrópica e características naturais do espaço. Boletim goiano de Geografia, v. 32, n. 1, p. 151-165, 2012.

Prado, R. M \& Natale, W. Calagem na nutrição de cálcio e no desenvolvimento do sistema radicular da goiabeira. Pesquisa Agropecuária Brasileira, v. 39, n. 10, 2004.

Reis, C. F. et al. Diagnóstico do setor de florestas plantadas no estado de Goiás. Brasília, DF: Embrapa, 2015.

Ruas, R. A. A. et al. Silvicultura de precisão na eucaliptocultura. In: Vale, A. B. et al. (Ed.). Eucaliptocultura no Brasil: silvicultura, manejo e ambiência. Viçosa, MG: SIF, 2014. p. 263-282.

Sadeghi, V. et al. A new model for automatic normalization of multitemporal satellite images using Artificial Neural Network and mathematical methods. Applied Mathematical Modelling, v. 37, p. 6437-6445, 2013. https://doi.org/10.1016/j.apm.2013.01.006.

Sano, E. E. et al. Mapeamento da cobertura vegetal do Bioma Cerrado: estratégias e resultados. Planaltina, DF: Embrapa Cerrados, 2007a.

Sano, E. E. et al. Padrões de cobertura de solos do estado de Goiás. In: Ferreira, L. G. (Org.). A encruzilhada socioambiental: biodiversidade, economia e sustentabilidade no cerrado. Goiânia: Ed. UFG, 2007b.

Shiba, M. H. et al. Classificação de imagens de sensoriamento remoto pela aprendizagem por árvore de decisão: uma avaliação de desempenho. In: SIMPÓSIO BRASILEIRO DE SENSORIAMENTO REMOTO, 12., 2005, Goiânia. Anais... São José dos Campos: INPE, 2005. p. 4319-4326.

Song, C. et al. The spectral/temporal manifestation of forest succession in optical imagery the potential of multitemporal imagery. Remote Sensing of Environment, v. 82, p. 285-302, 2002. https:// doi.org/10.1016/S0034-4257(02)00046-9.

Souza, C. C. et al. Técnicas de sensoriamento remoto como subsídios aos estudos de florestas implantadas no Brasil: uma revisão bibliográfica. Ciência Florestal, v. 17, n. 4, p. 409-417, 2007. http:// dx.doi.org/10.5902/198050981972.

Sousa, S. B. \& Ferreira, L. G. Mapeamento da cobertura e uso da terra: uma abordagem utilizando dados de sensoriamento remoto óptico multitemporais e provenientes de múltiplas plataformas. Revista Brasileira de Cartografia, n. 66, v. 2, 2014.

TerraClass: Cerrado. Uso do solo do Cerrado (2013). Disponível em: < http://maps.lapig .iesa.ufg.br/lapig.html>. Acesso em: 7 mar. de 2016. 
Wang, L. et al. Study on ecosytem service function change of island based on remote sensing. Acta Oceanologica Sinica, v. 34, n. 8, p. 100-107, 2015. https://doi.org/10.1007/s13131-015-0587-x.

Yadav, B. K. \& Nandy, S. Mapping aboveground woody biomass using forest inventory, remote sensing and geostatistical techniques. Environmental Monitoring Assessment, v. 187, n. 5, p. 1-12, 2015. https://doi.org/10.1007/s10661-015-4551-1.
Zhong, Y. \& Zhang, L. Remote sensing image subpixel mapping based on adaptive differential evolution. IEEE Transactions on Systems, Man, and Cybernetics, Part B: Cybernetics, v. 42, n. 5, p. 1306-1329, 2012. https://doi.org/10.1109/TSMCB.2012.2189561. 